\title{
Harms and benefits of sodium-glucose co-transporter 2 inhibitors
}

\section{Thomas Chesterman \\ Advanced trainee in \\ Endocrinology' \\ Associate lecturer ${ }^{2}$ \\ Tilenka RJ Thynne \\ Clinical pharmacologist and \\ Endocrinologist t,2,3 \\ 1 Southern Adelaide \\ Diabetes and Endocrine \\ Service, South Australia \\ Health \\ ${ }^{2}$ College of Medicine and \\ Public Health, Flinders \\ University \\ ${ }^{3}$ Department of Clinical Pharmacology, Flinders \\ Medical Centre, Flinders \\ University \\ Adelaide}

\section{Keywords}

canagliflozin, dapagliflozin, empagliflozin, ertugliflozin, diabetes

Aust Prescr 2020;43:168-71 https://doi.org/10.18773/ austprescr.2020.049

\section{SUMMARY}

Sodium-glucose co-transporter 2 inhibitors are oral glucose-lowering drugs that increase the urinary excretion of glucose. In patients with type 2 diabetes and cardiovascular disease they reduce all-cause mortality, cardiac mortality, rates of hospitalisation for heart failure and the progression of renal disease.

There are adverse effects related to the mechanism of action. These include polyuria and intravascular volume depletion from osmotic diuresis, and genitourinary infections from glycosuria. Ketoacidosis is a rare adverse effect.

The glucose-lowering efficacy of sodium-glucose co-transporter 2 inhibitors decreases with increasing renal impairment.

\section{Introduction}

The Australian Therapeutic Goods Administration (TGA) first approved sodium-glucose co-transporter 2 (SGLT2) inhibitors in 2013. There are now three SGLT2 inhibitors listed on the Pharmaceutical Benefits Scheme (PBS). They are available individually or in combination with other drugs, such as metformin (Table).

\section{Mechanism of action}

Each day the kidneys normally filter about $180 \mathrm{~g}$ of glucose, but over $90 \%$ is reabsorbed in the proximal renal tubule. This reabsorption is facilitated by SGLT2. Inhibiting this transporter reduces the renal threshold for glucose excretion, causing glycosuria.

SGLT2 inhibitors have a glucose-lowering effect which is independent of the insulin concentration or insulin
Table SGLT2 inhibitors listed on the Pharmaceutical Benefits Scheme

\begin{tabular}{lll}
\hline Generic & Brand names & Approved total daily dose \\
\hline Dapagliflozin & $\begin{array}{l}\text { Forxiga } \\
\text { Xigduo XR (dapagliflozin + modified- } \\
\text { release metformin) }\end{array}$ & $10 \mathrm{mg}$ \\
\hline Empagliflozin & $\begin{array}{l}\text { Jardiance } \\
\text { Jardiamet (empagliflozin + metformin) } \\
\text { Glyxambi (empagliflozin + linagliptin) }\end{array}$ & \\
\hline \multirow{2}{*}{ Ertugliflozin } & $\begin{array}{l}\text { Steglatro } \\
\text { Segluromet (ertugliflozin + metformin) }\end{array}$ & \\
& Steglujan (ertugliflozin + sitagliptin) & \\
\hline
\end{tabular}

resistance. They also have a diuretic effect. As there is a caloric loss of glucose in the urine, the drugs cause a small amount of weight loss.

The glucose-lowering effect depends on functioning renal tubules, so the efficacy of SGLT2 inhibitors reduces with increasing renal impairment. According to the product information, all three PBS-subsidised SGLT2 inhibitors are contraindicated when the estimated glomerular filtration rate (eGFR) is persistently below $45 \mathrm{~mL} / \mathrm{min} / 1.73 \mathrm{~m}^{2}$. This may change in the future as recent studies have shown benefits in patients with a lower eGFR. ${ }^{1-3}$

SGLT2 inhibitors increase ketone concentrations and ketone production. The precise mechanism is unclear. It may be due to an increase in the glucagon:insulin ratio leading to lipolysis, proteolysis, gluconeogenesis and ketone formation as well as modest intravascular volume contraction and increased renal reabsorption of ketones. ${ }^{4}$

\section{Benefits}

The glucose-lowering effect of SGLT2 inhibitors is comparable to that of other oral drugs for diabetes. Glycated haemoglobin (HbA1c) is reduced by 0.5-1\% compared to placebo. ${ }^{5,6}$ Greater HbA1c reductions are seen in patients with higher baseline HbAlc concentrations. ${ }^{7}$

SGLT2 inhibitors do not usually cause hypoglycaemia except when taken with insulin or sulfonylureas. ${ }^{8}$ Caloric loss from glycosuria leads to a mean weight loss of $2.5 \mathrm{~kg}$ at one year. ${ }^{5}$ SGLT2 inhibitors have a small but favourable effect on blood pressure. On average they lower systolic pressure by $4 \mathrm{mmHg}$ and diastolic pressure by $1.6 \mathrm{mmHg} .{ }^{9}$ 
Empagliflozin was studied in the EMPA-REG OUTCOME trial. This randomised controlled trial included over 7000 patients with type 2 diabetes and established cardiovascular disease. Those treated with empagliflozin had significantly lower rates of death from cardiovascular causes (38\% relative risk reduction). ${ }^{10}$ This was a surprise finding of the trial which had been designed to show a lack of cardiovascular harm. A meta-analysis of the three major cardiovascular outcome trials of empagliflozin, canagliflozin and dapagliflozin found a 15\% relative risk reduction in all-cause mortality and a 30\% relative risk reduction in hospitalisation for heart failure." However, the recently reported cardiovascular outcomes trial of ertugliflozin (VERTIS CV) failed to show a benefit above placebo with no significant reduction in the combined primary outcome of cardiovascular death, non-fatal myocardial infarction or non-fatal stroke. ${ }^{12}$ This does therefore question whether the cardiovascular benefits are a whole-of-class effect.

The SGLT2 inhibitors are beneficial in mild to moderate renal disease. While a transient decrease in eGFR can occur at the start of treatment this is not progressive. It is similar to the decreased eGFR seen when starting an ACE inhibitor. ${ }^{8}$ In patients with an eGFR close to $45 \mathrm{~mL} / \mathrm{min} / 1.73 \mathrm{~m}^{2}$ a drop to below $45 \mathrm{~mL} / \mathrm{min} / 1.73 \mathrm{~m}^{2}$ may be seen, however this is anticipated and not a reason to discontinue therapy. In the long term SGLT2 inhibitors are renoprotective, with a $45 \%$ relative risk reduction in the progression of renal disease (worsening eGFR, end-stage renal disease or renal death) compared to placebo."

\section{Adverse effects}

Some of the adverse effects can be predicted from the mechanisms of action of the SGLT2 inhibitors.

\section{Genitourinary infections}

SGLT2 inhibitors are associated with 3-5-fold increased risk of fungal genital infections (such as candidiasis). ${ }^{13}$ The infections occur more commonly in women and are generally mild. They may be treated with antifungal therapy and usually do not require the SGLT2 inhibitor to be stopped. Patients at higher risk include those with previous genital candidiasis and uncircumcised men. ${ }^{14}$

Some studies have found an association with urinary tract infections. However, recent meta-analyses have not found a relationship between infections and SGLT2 inhibitors, except for dapagliflozin. 13,15 Nonetheless, there have been postmarketing reports of pyelonephritis and complicated urinary tract infections in patients taking SGLT2 inhibitors. ${ }^{14}$

There have been case reports and case series of necrotising fasciitis of the perineum (also known as Fournier's gangrene) associated with SGLT2 inhibitors. ${ }^{16}$ However, in the dapagliflozin and cardiovascular outcomes in type 2 diabetes trial (DECLARE-TIMI 58) involving 17,160 patients there were five cases of Fournier's gangrene in the placebo group and only one in the dapagliflozin group. ${ }^{17}$ Furthermore, a meta-analysis of randomised controlled trials with over 69,000 patients in total found no increase in rates of Fournier's gangrene. Due to the small number of total events, this meta-analysis was unable to completely exclude an increased risk. ${ }^{18}$

\section{Volume depletion}

SGLT2 inhibitors are associated with a small increase in adverse effects related to intravascular volume depletion, such as hypotension, syncope and dehydration. ${ }^{14}$ In euvolaemic patients consider reducing the dose of any diuretics to avoid further volume depletion. SGLT2 inhibitors should be withheld when a patient is at risk of dehydration, such as during an episode of gastroenteritis, when systemically unwell and around medical and surgical procedures.

\section{Ketoacidosis}

SGLT2 inhibitors have been associated with an increased risk of diabetic ketoacidosis. A South Australian case series identified 13 cases of diabetic ketoacidosis over a 15-month period. ${ }^{19}$ Precipitants included missed insulin, undiagnosed type 1 diabetes, infection, fasting, and low-carbohydrate diets. ${ }^{19} \mathrm{~A}$ Victorian retrospective study also found an increased risk of diabetic ketoacidosis associated with SGLT2 inhibitors (odds ratio 1.48). Hospital inpatients had a markedly increased risk of developing diabetic ketoacidosis (odds ratio 37.4). ${ }^{20}$

Diabetic ketoacidosis in patients taking SGLT2 inhibitors can present with normal or only mildly elevated glucose concentrations. This is due to the ongoing SGLT2 inhibitor-induced glycosuria. It is therefore prudent to test for ketones in any unwell patient taking an SGLT2 inhibitor regardless of their blood glucose concentration.

The Australian Diabetes Society has published recommendations based on expert opinion to try to reduce the risk of perioperative diabetic ketoacidosis. ${ }^{21}$ Recommendations include withholding SGLT2 inhibitors for three days before major surgical procedures and not restarting them until the patient is eating and drinking. ${ }^{21}$

\section{Amputations}

An approximately twofold increased risk of lower limb amputations was observed with canagliflozin in the CANVAS trial. ${ }^{22}$ However, a second large randomised controlled trial of canagliflozin (CREDENCE) and a 
meta-analysis of four observational databases did not find a significantly increased risk. ${ }^{23,24}$ Higher rates of lower limb amputations were not seen in the EMPAREG OUTCOME ${ }^{25}$ or DECLARE-TIMI 58 trials. ${ }^{17}$

An analysis of reports to the World Health Organization suggests an increased risk of lower limb amputations with canagliflozin, empagliflozin and dapagliflozin. However, these results may have been confounded by reporting bias. $^{26}$

\section{Fractures}

Current data are inconclusive regarding SGLT2 inhibitors and fracture risk. In one study, canagliflozin was associated with decreased bone mineral density at the hip after two years of treatment. ${ }^{27}$ The CANVAS trial found an increased relative risk of fractures (hazard ratio 1.26) with canagliflozin. ${ }^{22}$ However, a meta-analysis of 38 randomised controlled trials did not find an overall increased risk of fractures with SGLT2 inhibitors. ${ }^{28}$ Most of these studies had followup periods of less than three years and further longterm studies are needed.

\section{Acute kidney injury}

A meta-analysis of randomised controlled trials found that SGLT2 inhibitors are associated with reduced rates of acute kidney injury, ${ }^{29}$ however there are numerous case reports of acute kidney injury occurring shortly after starting treatment. A transient decrease in eGFR may be seen after starting an SGLT2 inhibitor, but this does not usually progress.

\section{Emerging indications}

Currently, SGLT2 inhibitors are not approved by the TGA for patients without type 2 diabetes, but other indications are being studied.

\section{Heart failure in patients without diabetes}

The dapagliflozin heart failure randomised controlled trial (DAPA-HF) studied 4744 patients with heart

\section{SELF-TEST} QUESTIONS

True or false?

3. In a patient with normal kidney function, a transient decline in glomerular filtration after starting an SGLT2 inhibitor is an indication to stop treatment.

4. Diabetic ketoacidosis does not occur in patients with type 2 diabetes treated with an SGLT2 inhibitor.

Answers on page 179 failure and an ejection fraction less than $40 \% .{ }^{30}$ They were on optimal treatment for heart failure and did not have diabetes. Compared with placebo, there was a $26 \%$ relative risk reduction in worsening heart failure or cardiovascular death with dapagliflozin. There was no significant difference in adverse effects.

Ongoing studies of empagliflozin and dapagliflozin in patients with heart failure with preserved and reduced ejection fraction (EMPEROR-Reduced, EMPERORPreserved and DELIVER) will add to the evidence in this area.

\section{Type 1 diabetes}

Due to their non-insulin mediated mechanism of glycaemic control, there has been interest in using SGLT2 inhibitors for patients with type 1 diabetes. There are several trials in type 1 diabetes but they are of short duration (maximum 52 weeks). A small decrease in $\mathrm{HbA1c}$ is seen (on average $0.2-0.45 \%$ ) but at the cost of a $2-3$-fold increase in diabetic ketoacidosis. ${ }^{31}$

Dapagliflozin was approved in early 2019 by the European Medicines Agency for patients with type 1 diabetes who are overweight. However, the US Food and Drug Administration voted against approving empagliflozin.

The SGLT2 inhibitors are not approved in Australia for type 1 diabetes. Any off-label use should only be considered by diabetes specialists and their patients with a clear plan to reduce the risk of diabetic ketoacidosis, for example by ketone monitoring.

\section{The role of SGLT2 inhibitors in practice}

In type 2 diabetes there are many second-line options, both oral and injectable, which can be added to first-line metformin. The Australian Diabetes Society has published a treatment algorithm which provides guidance to practitioners. ${ }^{32}$ Key points include ensuring all patients receive education regarding lifestyle measures and weight management and individualising $\mathrm{HbAlc}$ targets. After metformin, add-on second-line pharmacotherapy includes sulfonylureas, SGLT2 inhibitors, dipeptidyl peptidase-4 inhibitors, insulin or glucagon-like peptide-1 receptor analogues. Choosing which drug is best involves balancing the harm-benefit for the individual patient. The risk of cardiovascular and renal disease should be assessed. Patients at higher cardiovascular risk (for example a previous event or known atherosclerosis), with heart failure, or with chronic kidney disease (but stable eGFR above $45 \mathrm{~mL} / \mathrm{min} / 1.73 \mathrm{~m}^{2}$ ) may benefit from SGLT2 inhibitors.

\section{Conclusion}

SGLT2 inhibitors are oral glucose-lowering drugs which cause modest weight loss and blood pressure reduction. They have low rates of hypoglycaemia, except when used in conjunction with insulin or sulfonylureas. In patients with type 2 diabetes and cardiovascular disease, SGLT2 inhibitors reduce allcause mortality, rates of hospitalisation for heart failure and the progression of renal disease.

Adverse effects are usually mild and related to glycosuria and osmotic diuresis. Serious adverse effects are rare, but may include diabetic ketoacidosis, severe genitourinary infections and possibly lower limb amputations and fractures. $<$

Conflict of interest: none declared 
1. Perkovic V, Jardine MJ, Neal B, Bompoint S, Heerspink HJ, Charytan DM, et al.; CREDENCE Trial Investigators. Canagliflozin and renal outcomes in type 2 diabetes and nephropathy. N Engl J Med 2019;380:2295-306. https://doi.org/ 10.1056/NEJMoa1811744

2. Wanner C, Lachin JM, Inzucchi SE, Fitchett D, Mattheus M, George J, et al.; EMPA-REG OUTCOME Investigators. Empagliflozin and clinical outcomes in patients with type 2 diabetes mellitus, established cardiovascular disease, and chronic kidney disease. Circulation 2018:137:119-29. https://doi.org/10.1161/ CIRCULATIONAHA.117.028268

3. Fioretto P, Del Prato S, Buse JB, Goldenberg R, Giorgino F, Reyner D, et al.; DERIVE Study Investigators. Efficacy and safety of dapagliflozin in patients with type 2 diabetes and moderate renal impairment (chronic kidney disease stage 3A): the DERIVE Study. Diabetes Obes Metab 2018;20:2532-40. https://doi.org/10.1111/dom.13413

4. Qiu H, Novikov A, Vallon V. Ketosis and diabetic ketoacidosis in response to SGLT2 inhibitors: Basic mechanisms and therapeutic perspectives. Diabetes Metab Res Rev 2017;33:e2886. https://doi.org/10.1002/dmrr.2886

5. Liu XY, Zhang N, Chen R, Zhao JG, Yu P. Efficacy and safety of sodiumglucose cotransporter 2 inhibitors in type 2 diabetes: a meta-analysis of randomized controlled trials for 1 to 2 years. J Diabetes Complications 2015;29:1295-303. https://doi.org/10.1016/j.jdiacomp.2015.07.011

6 Inzucchi SE, Bergenstal RM, Buse JB, Diamant M, Ferrannini E Nauck M, et al. Management of hyperglycaemia in type 2 diabetes, 2015: a patientcentred approach. Update to a position statement of the American Diabetes Association and the European Association for the Study of Diabetes. Diabetologia 2015;58:429-42. https://doi.org/10.1007/s00125-014-3460-0

7. Ferrannini E, Ramos SJ, Salsali A, Tang W, List JF. Dapagliflozin monotherapy in type 2 diabetic patients with inadequate glycemic control by diet and exercise: a randomized, double-blind, placebo-controlled, phase 3 trial. Diabetes Care 2010;33:2217-24. https://doi.org/10.2337/dc10-0612

8. DeFronzo RA, Norton L, Abdul-Ghani M. Renal, metabolic and cardiovascular considerations of SGLT2 inhibition. Nat Rev Nephrol 2017;13:11-26. https://doi.org/10.1038/nrneph.2016.170

9. Baker WL, Smyth LR, Riche DM, Bourret EM, Chamberlin KW, White WB. Effects of sodium-glucose co-transporter 2 inhibitors on blood pressure: a systematic review and meta-analysis. J Am Soc Hypertens 2014;8:262-75.e9. https://doi.org/10.1016/j.jash.2014.01.007

10. Zinman B, Wanner C, Lachin JM, Fitchett D, Bluhmki E, Hantel S, et al.; EMPAREG OUTCOME Investigators. Empagliflozin, cardiovascular outcomes, and mortality in type 2 diabetes. N Engl J Med 2015;373:2117-28. https://doi.org/ 10.1056/NEJMoa1504720

11. Zelniker TA, Wiviott SD, Raz I, Im K, Goodrich EL, Bonaca MP, et al. SGLT2 inhibitors for primary and secondary prevention of cardiovascular and renal outcomes in type 2 diabetes: a systematic review and meta-analysis of cardiovascular outcome trials. Lancet 2019;393:31-9. https://doi.org/10.1016/ S0140-6736(18)32590-X

12. Cannon CP. Evaluation of ertugliflozin efficacy and safety cardiovascular outcomes trial - VERTIS CV. Presented at the American Diabetes Association Virtual Scientific Sessions, 2020 Jun 16. https://www.acc.org/latest-incardiology/clinical-trials/2020/06/16/11/24/vertis [cited 2020 Sep 1]

13. Li D, Wang $T$, Shen S, Fang Z, Dong $Y$, Tang $H$. Urinary tract and genital infections in patients with type 2 diabetes treated with sodium-glucose co-transporter 2 inhibitors: a meta-analysis of randomized controlled trials. Diabetes Obes Metab 2017;19:348-55. https://doi.org/10.1111/dom.12825

14. McGill JB, Subramanian S. Safety of sodium-glucose co-transporter 2 inhibitors. Am J Cardiol 2019;124 Suppl 1:S45-52. PubMed https://doi.org/ 10.1016/j.amjcard.2019.10.029

15. Donnan JR, Grandy CA, Chibrikov E, PharmD CM, Aubrey-Bassler K, Johnston $\mathrm{K}$, et al. Dose response of sodium glucose cotransporter-2 inhibitors in relation to urinary tract infections: a systematic review and network metaanalysis of randomized controlled trials. CMAJ Open 2018;6:E594-602. https://doi.org/10.9778/cmajo.20180111

16. Bersoff-Matcha SJ, Chamberlain C, Cao C, Kortepeter C, Chong WH. Fournier gangrene associated with sodium-glucose cotransporter-2 inhibitors: a review of spontaneous postmarketing cases. Ann Intern Med 2019;170:764-9. https://doi.org/10.7326/M19-0085
17. Wiviott SD, Raz I, Bonaca MP, Mosenzon O, Kato ET, Cahn A, et al.; DECLARE-TIMI 58 Investigators. Dapagliflozin and cardiovascular outcomes in type 2 diabetes. N Engl J Med 2019;380:347-57. https://doi.org/10.1056/ NEJMoa1812389

18. Silverii GA, Dicembrini I, Monami M, Mannucci E. Fournier's gangrene and sodium-glucose co-transporter-2 inhibitors: a meta-analysis of randomized controlled trials. Diabetes Obes Metab 2020;22:272-5. https://doi.org/10.1111/ dom. 13900

19. Meyer EJ, Gabb G, Jesudason D. SGLT2 inhibitor-associated euglycemic diabetic ketoacidosis: a South Australian clinical case series and Australian spontaneous adverse event notifications. Diabetes Care 2018;41:e47-9. https://doi.org/10.2337/dc17-1721

20. Hamblin PS, Wong R, Ekinci El, Fourlanos S, Shah S, Jones AR, et al. SGLT2 Inhibitors increase the risk of diabetic ketoacidosis developing in the community and during hospital admission. J Clin Endocrinol Metab 2019;104:3077-87. https://doi.org/10.1210/jc.2019-00139

21. Australian Diabetes Society. ALERT - Diabetic ketoacidosis (DKA) with SGLT2 inhibitor use, particularly perioperatively. Sydney: ADS; 2019 Aug https://diabetessociety.com.au/position-statements.asp [cited 2020 Sep 1]

22. Neal B, Perkovic V, Mahaffey KW, de Zeeuw D, Fulcher G, Erondu N, et al.; CANVAS Program Collaborative Group. Canagliflozin and cardiovascular and renal events in type 2 diabetes. N Engl J Med 2017;377:644-57. https://doi.org/10.1056/NEJMoa1611925

23. Perkovic V, Jardine MJ, Neal B, Bompoint S, Heerspink HJ, Charytan DM, et al.; CREDENCE Trial Investigators. Canagliflozin and renal outcomes in type 2 diabetes and nephropathy. N Engl J Med 2019;380:2295-306. https://doi.org/ 10.1056/NEJMoa1811744

24. Ryan PB, Buse JB, Schuemie MJ, DeFalco F, Yuan Z, Stang PE, et al. Comparative effectiveness of canagliflozin, SGLT2 inhibitors and non-SGLT2 inhibitors on the risk of hospitalization for heart failure and amputation in patients with type 2 diabetes mellitus: a real-world meta-analysis of 4 observational databases (OBSERVE-4D). Diabetes Obes Metab 2018;20:2585-97. https://doi.org/10.1111/dom.13424

25. Inzucchi SE, lliev H, Pfarr E, Zinman B. Empagliflozin and assessment of lower-limb amputations in the EMPA-REG OUTCOME Trial. Diabetes Care 2018;41:e4-5. https://doi.org/10.2337/dc17-1551

26. Khouri C, Cracowski JL, Roustit M. SGLT-2 inhibitors and the risk of lowerlimb amputation: is this a class effect? Diabetes Obes Metab 2018;20:1531-4. https://doi.org/10.1111/dom.13255

27. Bilezikian JP, Watts NB, Usiskin K, Polidori D, Fung A, Sullivan D, et al. Evaluation of bone mineral density and bone biomarkers in patients with type 2 diabetes treated with canagliflozin. J Clin Endocrinol Metab 2016:101:44-51. https://doi.org/10.1210/jc.2015-1860

28. Tang HL, Li DD, Zhang JJ, Hsu YH, Wang TS, Zhai SD, et al. Lack of evidence for a harmful effect of sodium-glucose co-transporter 2 (SGLT2) inhibitors on fracture risk among type 2 diabetes patients: a network and cumulative metaanalysis of randomized controlled trials. Diabetes Obes Metab 2016;18:1199-206. https://doi.org/10.1111/dom.12742

29. Donnan JR, Grandy CA, Chibrikov E, Marra CA, Aubrey-Bassler K, Johnston K, et al. Comparative safety of the sodium glucose co-transporter 2 (SGLT2) inhibitors: a systematic review and meta-analysis. BMJ Open 2019;9:e022577. https://doi.org/10.1136/bmjopen-2018-022577

30. McMurray JJ, Solomon SD, Inzucchi SE, Køber L, Kosiborod MN, Martinez FA, et al.; DAPA-HF Trial Committees and Investigators. Dapagliflozin in patients with heart failure and reduced ejection fraction. N Engl J Med 2019;381:1995-2008. https://doi.org/10.1056/NEJMoa1911303

31. Danne T, Garg S, Peters AL, Buse JB, Mathieu C, Pettus JH, et al. International consensus on risk management of diabetic ketoacidosis in patients with type 1 diabetes treated with sodium-glucose cotransporter (SGLT) inhibitors. Diabetes Care 2019;42:1147-54. https://doi.org/10.2337/dc18-2316

32. Australian Diabetes Society. Type 2 diabetes treatment: a new blood glucose management algorithm for type 2 diabetes. ADS; 2020 Dec. http://t2d.diabetessociety.com.au [cited 2020 Sep 1] 